\title{
EFFECT OF DURATION SPENT IN SITTING POSTURE ON SADDLE BLOCK ANAESTHESIA WITH 0.5\% HYPERBARIC BUPIVACAINE.
}

Suresh Y. V, Neeta. S.

1. Associate Professor. Department of Anaesthesiology, Kasturba Medical College, Mangalore.

2. Assistant Professor. Department of Anaesthesiology, Kasturba Medical College, Mangalore.

\section{CORRESPONDING AUTHOR:}

Dr. Suresh Y. V,

Flat No.203,

Divya Enclave,

M.G.Road, Mangalore, Karnataka.

E-mail: drsureshyv@hotmail.com

Ph: 00919845085108

ABSTRACT: Spinal anesthesia causes hypotension and in some cases bradycardia. Making the patient to sit for different period after spinal anesthesia, we can reduce these complications and achieve the desired level of anesthesia and analgesia for perineal, few gynecological procedures $\&$ urological surgeries.

INTRODUCTION: Subarachnoid block is a popular and commonly used technique of regional anaesthesia. It is often preferred for efficacy, rapidity, minimal effects on body physiology and reduction of blood loss. The most commonly associated complication with spinal anaesthesia is hypotension and bradycardia. Which mainly depends on level of block achieved either due to the drugs used (i.e hypobaric or hyperbaric) or position of the patient after anesthesia with head high or low tilt. Other causes are age, the disease pattern etc.

A spinal (regional anesthesia) technique that prevents unnecessary higher levels of analgesia and sympathetic blockade is therefore recommended. This study examines the effect of different duration of sitting period required before the patient is placed in supine position, on spread of analgesia; extend of motor blockade and sympathetic blockade following subarachnoid administration of hyperbaric bupivacaine. $0.5 \%$

AIMS:

1. The influence of different periods of sitting before the patient is placed in supine horizontal position on the spread of analgesia and extent of motor blockade following subarachnoid administration of hyperbaric bupivacaine.(0.5\%)

2. To study the hemodynamic changes associated with the duration spent in sitting posture after giving spinal anaesthesia in sitting position.

METHODS: After obtaining approval from Medical Ethics Committee and written informed consent of patients, the prospective randomized clinical study was carried out on 60 patients belonging to ASA I and II, posted for minor urological procedures or perineal surgeries under spinal anaesthesia. The study was carried out in Kasturba Medical College Mangalore. Inclusion criteria include ASA group I and II patients in the age group between 25-65 years, of both sexes having comparable heights of $150-180 \mathrm{~cm}$ and weights of $50-80 \mathrm{kgs}$. 
A thorough preanaesthetic evaluation was carried out on all patients. Patients were premedicated with diazepam orally according to their weight $0.2-0.3 \mathrm{mg} / \mathrm{kg}$, one hour before induction of spinal anaesthesia. They were preloaded with $500 \mathrm{ml}$ normal saline by rapid intravenous infusion.

After attaching monitors baseline vitals were recorded, patients were placed in sitting position. Under strict aseptic precautions lumbar puncture was done using 23G QB needle using a midline approach at L2-3interspace.The skin is on filtrated with local anesthesia, $.2 .5 \mathrm{ml}$ of $0.5 \%$ bupivacaine heavy was injected into subarachnoid space. Patients were maintained in sitting posture for $2 \min$ (group $A, n=15$ ), 5 min (group $B, n=15$ ) $10 \min$ (group $C, n=15$ ), 15 min (group $\mathrm{D}, \mathrm{n}=15$ ). They were then placed in supine position.

Analgesia was assessed bilaterally in anterior axillary line by pinprick method, using a short bevelled 25 gauge needle every 5 min after supine position

Motor blockade of lower limb was evaluated by asking the patients to lift the extended leg at 5 minutes interval for $30 \mathrm{~min}$ and then at 45 and 60 minutes. Movement at hip, knee and ankle joints noted. Scoring for motor blockade done as, 0 - Complete flexion, 1 - Partial movement, 2 - No movement. Total score is 12 , which means complete blockade.

Systemic arterial pressure and heart rate were monitored before and after giving spinal anaesthesia and throughout the procedure at every $2 \mathrm{~min}$ for $10 \mathrm{~min}$, then $5 \mathrm{~min}$ interval for $30 \mathrm{~min}$ and then at 45 and $60 \mathrm{~min}$.Fall in blood pressure $>30 \%$ was treated with $5 \mathrm{mg}$ ephedrine given intravenously. Bradycardia, heart rate less than 40 beats per minute was treated with $0.6 \mathrm{mg}$ atropine IV.

The data were collected in forms. Data analysis was carried out using Chi-square test of significance and students ' $t$ ' test (SPSS version 16.0 was used for statistical analysis)

RESULTS: Most of the patients were in the age group of $30-40$ years.66\% were male patients and $34 \%$ were female patients. The difference of proportion of subjects observed between the study groups with respect to gender was not statistically significant. 'p'>0.05

\section{Table 1 Demographic data}

Total 60 patients were randomly selected for the study between the age group of 25 years to 65 years. The average age in Group A was 40years; in Group B was 34years; in Group C was 40 years and in Group D is 38 years.

\begin{tabular}{|l|l|l|l|l|l|}
\hline GROUP & & $\mathrm{An}=15$ & $\mathrm{Bn}=15$ & $\mathrm{C} \mathrm{n}=15$ & $\mathrm{D} \mathrm{n}=15$ \\
\hline AGE (years) & & $40 \pm 9$ & $34 \pm 8$ & $40 \pm 2$ & $38 \pm 2$ \\
\hline SEX & MALE & 10 & 8 & 12 & 10 \\
\hline & FEMALE & 5 & 7 & 3 & 5 \\
\hline
\end{tabular}

Heart rate variability of four groups, statistically significant difference was found in all four groups at 6 minutes $\mathrm{p}<0.05$. Systolic blood pressure showed statistically significant variations starting from fifteen minutes $p<0.05$. Significant hypotension was observed in group A after intrathecal administration of bupivacaine which was corrected with fluids and ephedrine.

Diastolic blood pressure showed statistically significant variations four minutes after giving spinal anaesthesia. $\mathrm{p}<0.05$. 
The maximal level of sensory blockade attained was in Group A uptoT4, Group B up to T6 Group C up to T8, Group D up to T10.

Motor block -Group A, Hip joint - By 10 minutes 100\% had complete blockade of both lower limbs .Knee joint - There were no patients without any block. $100 \%$ had complete blockade of knee joint .Ankle joint - All the patients had complete blockade by 5 minutes and continued till the end of the block over both lower limbs. Group B, Hip joint - 100\% of the patients had complete blockade of hip joint within 5 minutes. Knee joint - $80 \%$ had complete blockade and $20 \%$ had partial blockade. Ankle joint $-80 \%$ of patients had complete ankle blockade by 10 minutes, 20\% had partial blockade .Group C Hip joint - within 10 minutes $80 \%$ had complete block, 20\% partial .Knee joint - 60\% had complete knee joint blockade and 20\% had partial blockade $20 \%$ no block .Ankle joint - 50\% had no blockade while $30 \%$ had partial and $20 \%$ complete blockade. Group D ,Hip joint $20 \%$ of the patients had no blockade of hip joint, $40 \%$ had partial blockade, $40 \%$ had complete blockade .Knee joint - $20 \%$ had no motor blockade. $40 \%$ had partial blockade and $40 \%$ complete blockade. Ankle joint - 70\% had no blockade, $20 \%$ had partial blockade and $10 \%$ had complete blockade. Statistically significant difference in motor blockade was found between 4 groups within 5 minutes after giving spinal (saddle anaesthesia) anaesthesia $(\mathrm{p}<0.05)$

DISCUSSION: Spinal anaesthesia is a technique, which is used widely for many years. Effort to improve the quality of anaesthesia for patient is the aim of all practising anaesthesiologists.

Studies have shown hemodynamic stability on extended periods of sitting in saddle block. In view of this, various studies were conducted to establish the time period required in sitting posture before making the patient in lying [supine)position, on the ascend of drug and motor blockade.

There is lack of information regarding advantage and disadvantage of different patient position during the initiation of spinal anaesthesia. The choice of the patient position usually depends on the preference of the anaesthesiologist or patient, physical characteristics of the patient, or the baricity of the drug used.

Infact, the position of the patient and baricity of the solution injected as the determinants of distribution of drug in CSF are closely related. It has been reported that spinal block level increases by positional changes even after 60 minutes injection of local anaesthetic. However, the influence of body position on spread of local anaesthetic decreases with time after injection.

Here we conducted a clinical study to find out the effect of time duration spent in sitting posture against clinically achieved segmental levels, motor blockade and hemodynamic stability. This study shows that the extent of duration spent in sitting position after spinal (saddle) anaesthesia limits the cephalad spread of anaesthetic agent and extend the degree of motor and sensory blockade.

The cardiovascular stability (haemodynamic) was better with longer duration spent in sitting posture.

Vallathetal did prospective randomized study on 150 patients who received saddle block anaesthesia with $3 \mathrm{ml}$ of $0.5 \%$ bupivacaine. The period of sitting was $0 \mathrm{~min}, 2 \mathrm{~min}, 5 \mathrm{~min}$, $10 \mathrm{~min}$, and $15 \mathrm{~min}$. The incidence of negative deviations of HR and BP from baseline and usage of vasopressor was lesser in patients who sat longer during $90 \mathrm{~min}$ period .The maximal cephalad spread of analgesia also showed statistical significance. The results of this study were 
comparable with our study results, which had limited block and better cardiovascular stability with extended period of sitting 1 .

Schinther HR, Janke A, gave saddle block anaesthesia for 40 patients with $2 \mathrm{ml} 0.5 \%$ bupivacaine, posted for transanal surgeries. Success rate was $99.5 \%$ with increased duration of sensory block, level as long as the time until $1^{\text {st }}$ mobilization and micturition ${ }^{2}$.

Almost similar study was done by Gudatyle, Murchestine, who did study to find the minimal effective dose of spinal hyperbaric bupivacaine for adult anorectal surgeries. 93 patients were studied. The volume of drug injected was $1.5 \mathrm{ml}, 1 \mathrm{ml}$ and $0.8 \mathrm{ml}$ and patient were made to sit for $10 \mathrm{~min}$. Quality of block was found excellent in all groups with hemodynamic stability and restricted motor blockade ${ }^{3}$.

Sinclair and colleagues observed that spinal block level could not be significantly increased by the trendelenburg position after injection of $3 \mathrm{ml}$ of $0.5 \%$ bupivacaine injected intrathecally, compared with horizontal position. The reason could be due to the fixing of the drug with passage of time. This study agrees with the early observations of relative hemodynamic stability in patients sitting longer after subarachnoid block, also restricted block level with passage of time 4 . These findings were almost similar to the findings reported by wild smith etal; who demonstrated that $15 \mathrm{mg}$ of tetracaine injected with patients in lateral position and then made supine position immediately, resulted in significantly higher level of anaesthesia than when injected with patients in sitting position, the position being maintained for $2 \mathrm{~min}$ and then made supine. In addition, time taken for the development of peak sensory block level to pinprick and maximal motor block were shorter in lateral group compared with sitting group. The hemodynamic effects also show lesser ephedrine requirements in sitting group than lateral group. The decrease in hemodynamic response in sitting group results from slow spread of local anesthetic ${ }^{5}$.

In our study bradycardia was noted is 2 patients in group $A$, and 1 patient in group $B$ but not in Group C and Group D

Nausea, vomiting was seen in patients who had considerable decrease in blood pressure. $40 \%$ of patients in group A required rescue drug for hypotension while only $13 \%$ required in group $B$ and none of the patients in group $C \&$ D required rescue drug.

Hence it was observed that cardiovascular stability was better achieved with extended periods of sitting. The rationale behind the observation could be that, hyperbaric solution collects in a restricted volume of CSF and the drugs get partly fixed and partly absorbed with passage of time so that further change in position will not effect the blockade. None of the patients had pain during surgical procedure.

CONCLUSION: The present study demonstrates that as the duration spent in sitting position is increased, the restriction of sensory and motor blockade occurs to the most caudal spinal nerve roots. All patients experienced no discomfort with respect to surgical manipulations. This is a safe technique for perineal surgeries and some urological procedures, where patient will have least effect of the drug on the normal physiology.

\section{REFERENCES:}

1. Vallathetal .Effectiveness of duration spent in sitting posture on the spread of $3 \mathrm{ml}$ of $0.5 \%$ hyperbaric bupivacaine in subarachnoid block .J AnesthPharmacol 2005; $21 ; 155$ 157. 
2. Schimitter MD, Janke A, Weiss C. Practicability and patients subjective experiences of low dose spinal anesthesia using hyperbaric bupivacaine for transanal surgery; Int J colorectal dis 2009 Jul; 24(7): 827-36.

3. Gudactyle, Marchestine.Minimal effective dose of hyperbaric bupivacaine for adult anorectal surgeries. Anaesthesiology 2003;66:98-112

4. Sinclair colleagues. Effect of trendelenberg position on spinal anaesthesia with hyperbaric bupivacaine. B J Anesth 1982; 54:497-500.

5. Wildsmith J A, MC Claire J H. Effect of posture on spread of isobaric and hyperbaric amethocaine. B J Aneasth 1981;53:27

6. Spinal perianal block- a prospective randomized double blind comparison with spinal saddle block ;AnesthAnalg 2007 Jun; 104 (6) :159-4.

7. B.T Verring et al .Spinal anaesthesia with $0.5 \%$ bupivacaine in elderly patients, effect of duration spent in sitting posture. Br J Anesth 2001; 87:738-2.

8. Poveyetal. Subarachnoid analgesia with hyperbaric $0.5 \%$ bupivacaine; effect of $60 \mathrm{~min}$ period of sitting; ActaAnaesthesiolScand 1987;31:616-9 .

9. Medhat et al (2007). Spinal perianal block: A Prospective randomized double blind comparison with spinal saddle block. AnesthAnalg 2007; 104; 1594-6.

\section{Heart Rate}

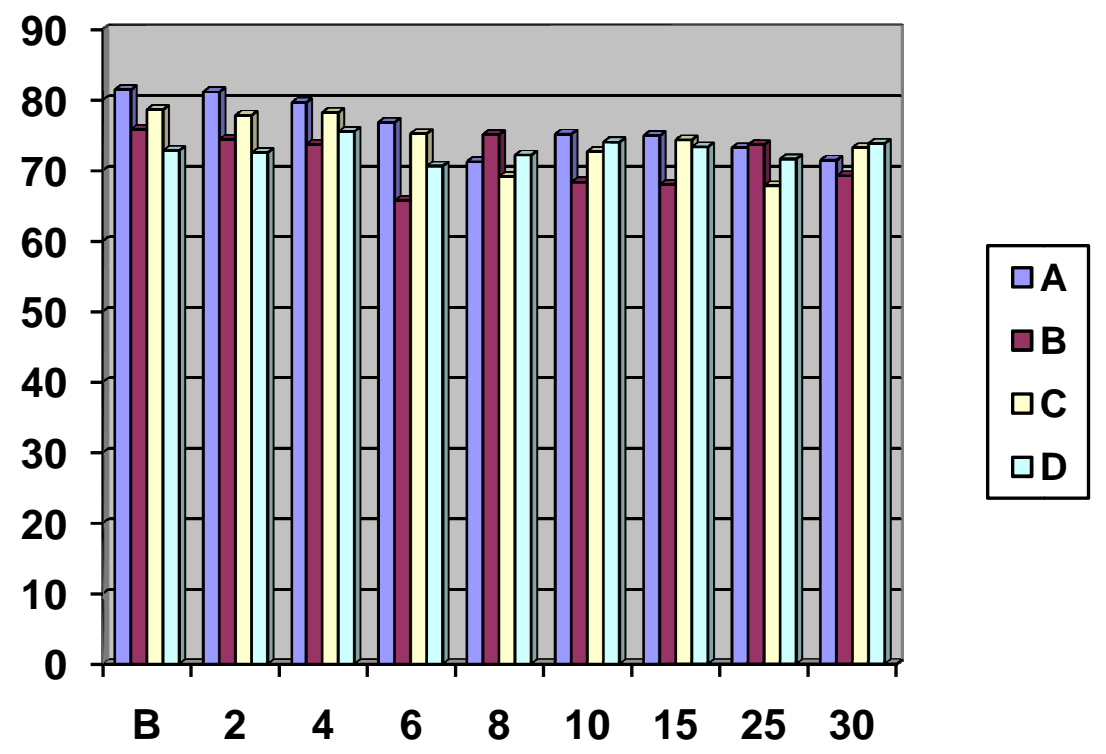

\section{Time}

\section{FIGURE 1: HEART RATE VARIABILITY}

Heart rate variability of four groups, statistically significant difference was found in all four groups at 6 minutes $\mathrm{p}<0.05$. 
FIGURE 2: SYSTOLIC BLOOD PRESSURE

BP

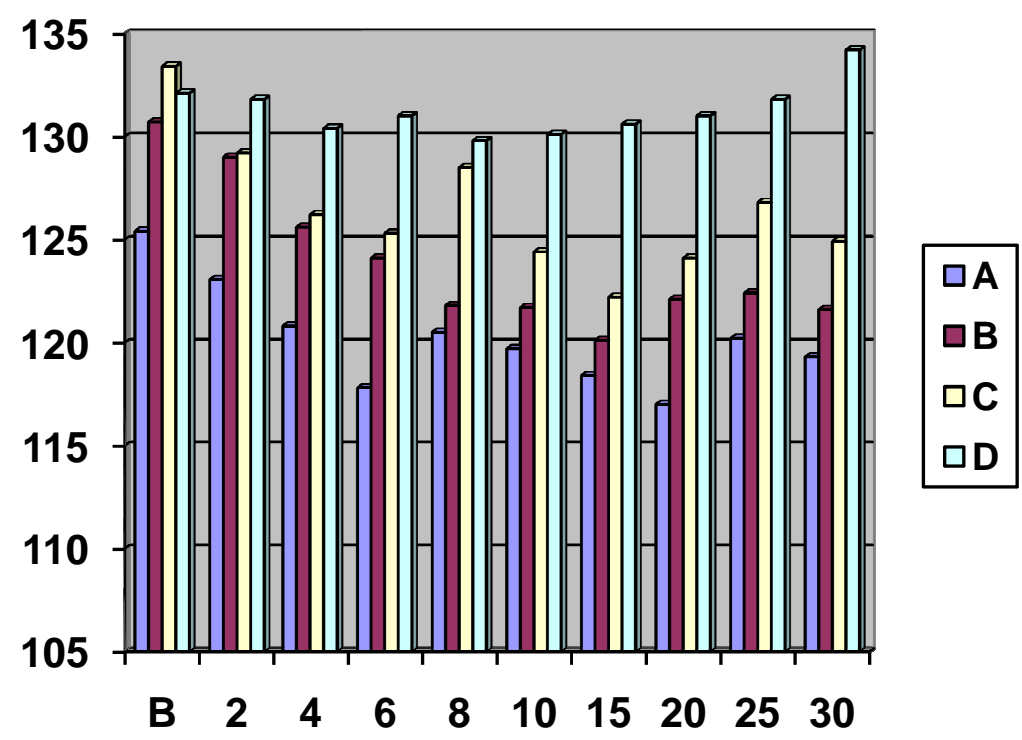

TIME: Systolic blood pressure showed statistically significant variations starting from fifteen minutes $\mathrm{p}<0.05$. Significant hypotension was observed in group A after intrathecal administration of bupivacaine which was corrected with fluids and ephedrine.

Figure 3: DIASTOLIC BLOOD PRESSURE

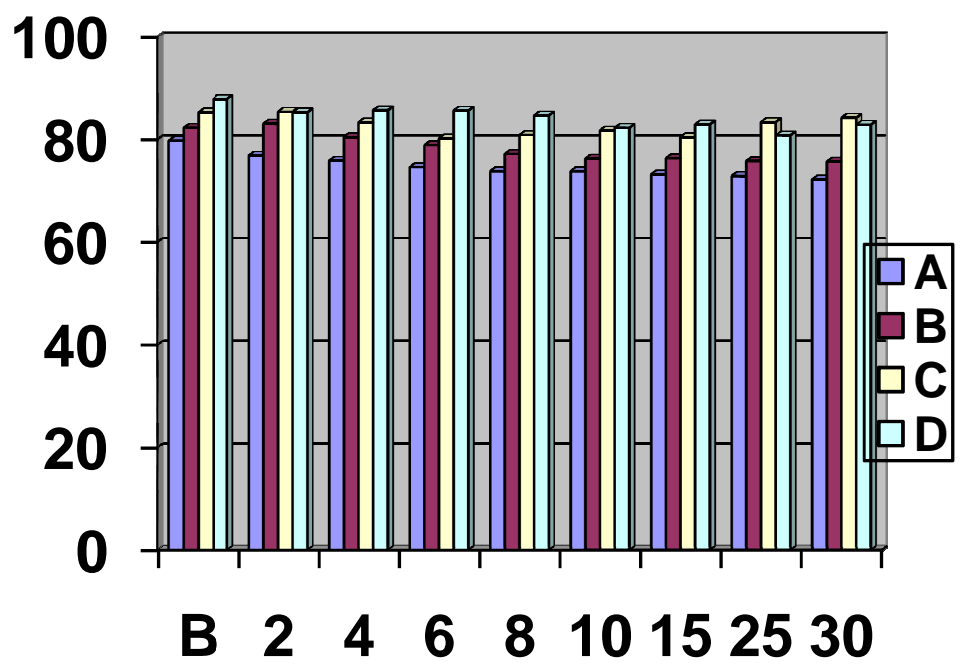

TIME Diastolic blood pressure showed statistically significant variations four minutes after giving spinal anesthesia. $\mathrm{p}<0.05$ 


\section{FIGURE 4: SENSORY BLOCKADE LOWER LIMB}

Maximum level of sensory blocked is up to T4 is seen in Group A, in Group B \& C is T8,where as in Group D is T10 . TIME

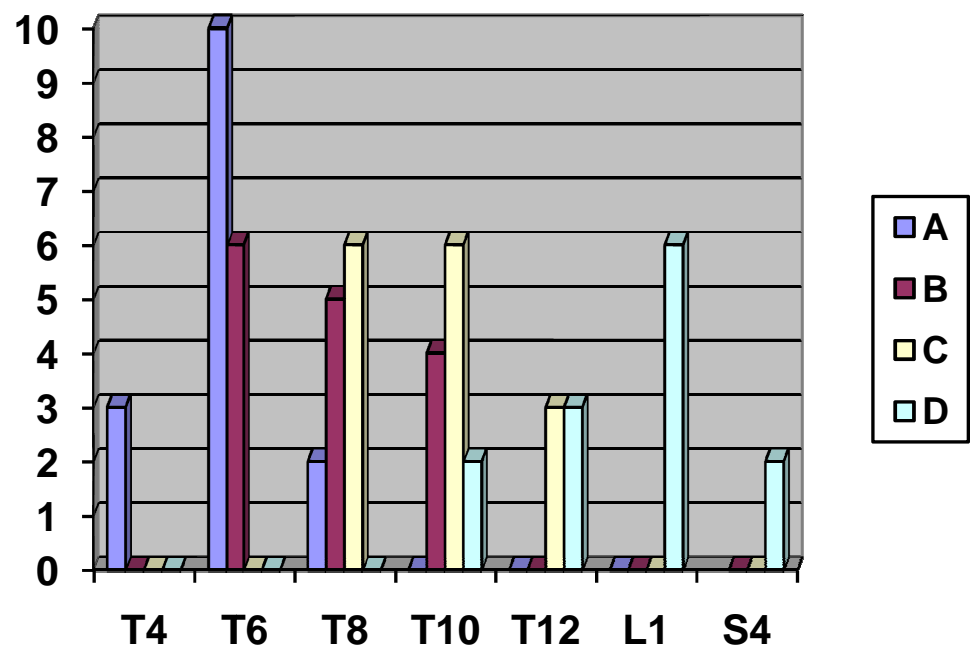

LEVEL Group A - The maximal level attained - T4

Group B - The maximal level attained - T6

Group C- The maximal level attained - T8

Group D- The maximal level attained - T10

FIGURE 5: MOTOR BLOCKADE LOWER LIMBBLOCKADE

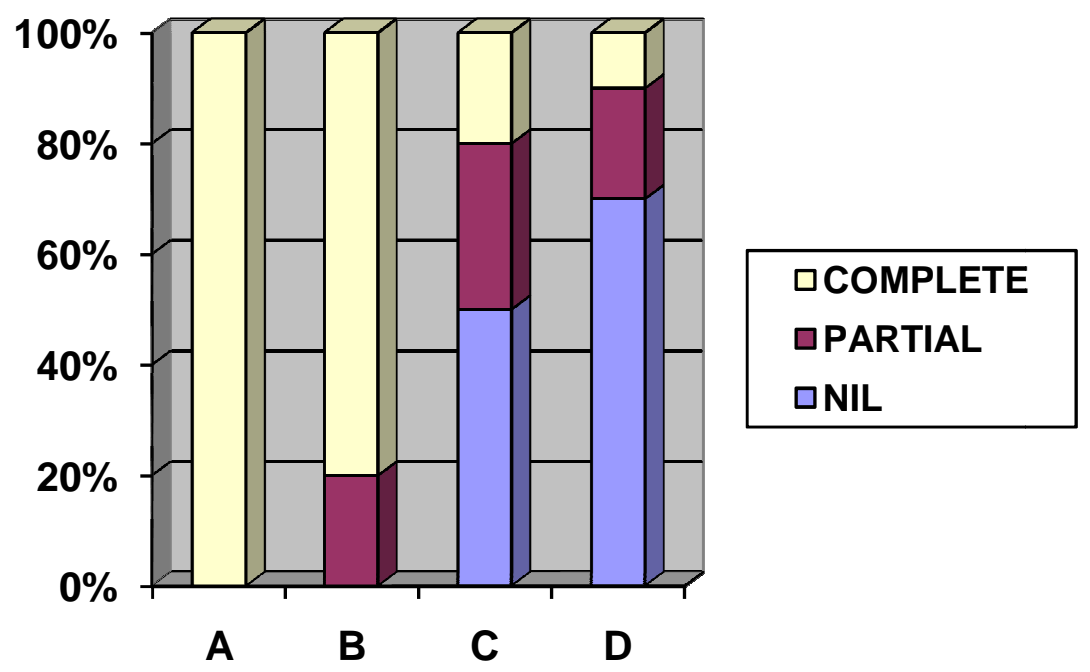

TIME

Group A - 100\% patients had complete blockade of lower limb.

Group B - 80\% complete blockade, while 20\% partial blockade

Group C - 50\% had no blockade 30\% had partial blockade $20 \%$ complete blockade Group D - 70\% had no blockade, 20\% had partial blockade,10\%complete blockade 